\title{
Opportunities and challenges for social sciences in the aftermath of the COVID-19 pandemic
}

The global pandemic of COVID-19 poses multiple challenges to the world order as it has evolved up to now. This includes industry, world trade, travel, education system, health care services and human security. A serious self-reflection is necessary within the sphere of social sciences so as to the nature of knowledge production we are currently engaged in and how to address challenges posed by the coronavirus for ethics of research, methods used and epistemological framework in general. More importantly, social sciences have a crucial role to play in understanding the nature of the pandemic itself, its impact on life, livelihoods, economic processes, social support mechanisms, vulnerable groups in society, social harmony and international relations, to list a few areas of direct relevance to social sciences. My argument in this editorial is that while the pandemic poses a real threat to the current mode of operation in social sciences globally, this may perhaps be a blessing in disguise in so far as we take account of the need to revamp our theories and approaches towards understanding human co-existence with each other but also with viruses, microbes and many other living entities ('actants' from the angle of Science and Technology scholars such as Bruno Latour 1997) in a rapidly changing global environment with shrinking resources and a wide variety of social, ecological and economic challenges.

\section{The challenges}

The challenges for social sciences in the post-COVID world order are both methodological and theoretical. They call for a radical change in our current mode of operation as well as the way we conceptualise the society we live in and the Anthropocene we have been part of. Let us start with the more immediate methodological dilemmas.

\section{Methodological challenges}

Social science research will be seriously affected by ethical and logistic difficulties presented by the novel corona virus, its responses and impacts. The difficulties relate to restrictions imposed by public health authorities for travel, human gathering, quarantine requirements for reseachers visiting from overseas as well as social distancing and hand washing requirements in field settings where running water, sanitizers and other requirements may not be readily available. Social science research heavily depends on direct interpersonal contacts between the researcher(s) and community members where rapport building is a prerequisite and long conversations, revisits and cross checking are essential part of the research process. Feasibility of these strategies may be restricted in a post-COVID setting where subsequent attacks of the epidemic have not been ruled out with a reported second attack currently taking shape in China and South Korea.

In a recent article on "Resuming field research in pandemic times" reported in SSRC website, Wood, Rogers, Sivaramakrishnan and Almeling (2020) argued that intensive field research of the type we are accustomed to may not be feasible in the near future in most countries for a combination of factors. First, the course of the pandemic, its consequences and outcomes are profoundly uncertain and as at present, the nature of the virus itself is not well known. For instance, whether infection confers immunity and how far and under what circumstances a second wave of the epidemic will unfold are unknown as at present. Similarly, how authorities and the public will react to outside researchers visiting them in the aftermath of the pandemic adds to the aura of uncertainties for some time even after the pandemic has ended.

Second, for potential subjects of many social research, life will be in turmoil or at least destabilised for some time. This includes migrant workers, informal sector operators, hawkers, tuk tuk drivers and many other vulnerable categories whose livelihoods were seriously jolted by COVID-19 related restrictions, shutdowns and 
embargos. In this environment, the researchers will have to think twice before deciding on their research topics and potential research subjects in order make sure that the research process will not add to their difficulties and may even endanger their lives.

Third, any social research technique that involves close physical proximity to the subjects, such as in-depth interviews will be difficult with social distancing and wearing of masks. This is likely to influence the quality of data gathering and analysis in much of social science research.

Finally, ensuring how the researcher him/herself will not be a vector of disease infection, especially where the researcher comes from outside the country where the research takes place as it often happens in anthropological research, will be another challenge that has serious ethical and pragmatic implications.

All these additional considerations will have to be factored into designing and implementing research as well as ethics review processes in post-COVID scenarios. Research in some social science disciplines will be more affected by the relevant restrictions because of the very nature of knowledge production in these subjects. For instance, referring to ethnographic research, the primary research methodology adopted in anthropological research, the above writers noted the following.

"Ethnographic and other in-person field research is likely to be among the last areas of scholarship that is able to return to some semblance of normalcy, and this process will unfold very unevenly, as local health, political, and social conditions will vary, as will host country restrictions" (Wood et al., 2020).

This, however, does not mean that this is the end of the world for anthropology and other social sciences relying heavily on first-hand information gathered through intensive field research.

We will have to think innovatively and creatively to address the methodological challenges posed by COVID-19. Here are some initial thoughts on the subject partly inspired by the above essay.

Remote research may be possible on some research topics using platforms such as Zoom, Microsoft Teams and Microsoft Classroom. Key informant interviews using remote research may be possible with a certain category of persons who are IT savvy and willing to talk about the selected topic without a direct face-to-face encounter. We can even conduct a focus group discussion with a group of people using the same platforms with more time spent on explaining questions on the part of the researchers. Online surveys already play a significant role in social research in economically advanced countries in Europe, North America and elsewhere. This is likely to increase and expand to developing countries as well in post-COVID settings. Social media can be a tool as well as a subject of research as is evident in the expanding volume of research on hate speech targeting specific communities during the pandemic itself (Silva, 2020). A number of recent studies on the impact of isolation and segregation caused by the pandemic in countries such as the US relies on daily diaries maintained by the subjects of research periodically monitored by the researchers. With high literacy and wide availability of smart phones, this research methodology may be feasible at least in some situations in Sri Lanka as well.

Partnerships with local researchers may be a necessity in post-COVID world where the researchers from global centres of learning wants to initiate international research covering other countries or a researcher wants to engage in research in another area within the same country. Partnerships must be based on sharing of knowledge production and benefits of research across national and regional boundaries. Hopefully this will lead to a more egalitarian social science knowledge production where current global monopolies in knowledge production will be gradually eliminated and peripheries will get a fair chance to be producers of their own knowledge that responds to local realities and requirements.

Exposure to the pandemic can also be a trigger for increased interdisciplinary collaboration. This is because the pandemic created an environment where solutions to most acute problems do not come from separate disciplines working in isolation from one another. For instance, sophisticated interdisciplinary research involving western medicine and ayurveda may be needed in order to determine how far and in what ways herbal remedies provide relief to COVID-19 patients. More relevant from the angle of applied social science research will be potential collaborations between psychology and sociology for overcoming stigma experienced by COVID-19 patients and their family members. Commenting on lessons learnt from the Ebola crisis of 2013-16, Margaret Chan, former Director-General of the World Health Organization, acknowledged that "inadequate engagement with affected communities and families" posed a significant obstacle in developing an effective response and called for "multidisciplinary approaches to community engagement, informed by anthropology and other social sciences" (Metzler, 2020).

\section{Analytical challenges}

Conceptual and hygienic tools for responding to the COVID-19 crisis evolved in western countries with a specific background in science and technology and 
sanitation development. Ideas such as social distancing, quarantine and respiratory hygiene may not mean the same thing in different cultures and even different people broadly sharing the same cultural landscape. For instance, social distancing is commonly understood as a means of reproducing caste, class and gender divides in the South Asian context and how COVID-19 related social distancing operates in such a context requires culturally informed social analysis. What is involved in this hygienic practice is physical distancing among people who are in active or passive interaction with each other in a given encounter so as to avoid momentary infection and not social distancing of a durable nature as implied by the term. It has to be stated here that physical distancing does not necessarily mean social distancing in an environment where mobile phones, email, WhatsApp and Skype can be effectively used to sustain social bonds among individuals who are a long way away from each other. Symbolic interactionist type social analysis, updated and modified as necessary in the light of globalized response to the pandemic, can be relevant to explore how physical distancing and wearing of masks interferes in social interaction in diverse social settings and possible ways of enhancing compliance by better integration of socio-cultural sensitivities.

Old social cleavages are likely to resurface perhaps in new forms and new social cleavages are likely to emerge in the wake of COVID-19 pandemic. Migrant workers in India stranded without food and incomes thousands of kilometres away from their homes following the sudden lockdown drive home the point that many of these migrant workers are from Dalit backgrounds experiencing discrimination and social distancing of a different sort. Arundhati Roy, who has been campaigning to draw attention to the pathetic condition of the workers affected by the lockdown as well as exposure to infection, noted

"In India only the elite could physically distance themselves. The poor were physically compressed in slums, in tiny homes, in unauthorized colonies. While Operation Vande Bharat flew Indians stranded in foreign countries home, millions of desperate working class people stranded in cities with no shelter, food or money, and no transport, began walking thousands of kilometres home to their villages. Hundreds of thousands were forcibly held in quarantine camps and then allowed to leave, jammed in buses and trains, carrying the virus with them...millions are out of work. Hunger is setting in. What is happening in those villages that people have returned to? Casteism, feudalism, sexism... in moments of such fear, despair and want how will people manage?" (Roy 2020).
It has to be noted here that this is not just resurfacing of caste as it was before, but an entirely new configuration where Dalits have become the new working class in neoliberal India, unprotected by either the labour laws under the Indian constitution or the moral foundation of the so-called jajmani system with some basic guarantees of livelihoods and subsistence accompanied by horizontal inequalities of a durable nature.

The plight of African Americans in the US during the pandemic has been similar in some respects. They have had a disproportionate COVID-19 burden. They have been the worst affected in terms of loss of employment in the wake of lockdown. They have also been the most vulnerable to mass infections reported in several prisons. On top of all these, the cold-blooded murder of George Floyd by a white police officer during a routine raid, drove home the point that they were the subjects of collateral damage caused by the pandemic as well as direct victims of the pandemic in many instances. This reveals the reproduction of racism in multiple forms in the pandemic-hit world superpower. In many contexts the pandemic appears to have the worst impact on the socially excluded. The massive social protests around Black-Lives-Matter (BLM) movement in the US and elsewhere perhaps point to the beginning of a new era of social protests emanating from the subalterns affected by layers upon layers of social discrimination plus the pandemic impact in different contexts.

The prejudices and agitations against migrants already gaining momentum in right wing mobilisations in Europe and USA will be reinforced due to the impact of the pandemic. As an example, the Chinese and Chineselooking students and workers in a number of European countries and in the US experienced discrimination in the immediate aftermath of the onset of the epidemic in China and South Korea. This compelled many of the affected persons to go back to their original countries before the travel restrictions were imposed. However, others had no escape but to live with these prejudices on a daily basis. A similar process was in operation in India where Chinese-looking students and workers from North Eastern states working elsewhere in India were targeted for stigmatisation in universities, work places, hostels and the like. These are some new social cleavages emerging with potential for increased social tension in the wake of the pandemic.

These new developments are challenges for social analysis as they do not lend themselves to straightforward interpretation using existing conceptual tools. While the pandemic was one of the most globalised events ever recorded, it threw up the downside of globalisation and a sudden halt in globalisation processes as they had 
unfolded up to that point in time. The pandemic itself unfolded globally with travel bans intended to halt the progress of the epidemic. This was the first ever international travel ban operating for such a long time covering most parts of the world simultaneously. On the whole, the pandemic points to the need to question the viability of the globalisation and liberalisation framework as the guiding design for the future of human kind in the light of intractable social and ecological challenges encountered by the world.

With nearly one-fourth of its work force currently employed overseas and many Sri Lankans studying abroad, the returnees from various countries contributed to the epidemic in Sri Lanka. The returnees from Italy drove the epidemic in the early stages and returnees from other countries posed challenges towards control of the epidemic in latter stages (Silva, 2020). Well organised quarantine processes, effective contact tracing and good public health services in Sri Lanka contributed to the successful containment of the epidemic so far in spite of the challenges posed by many Sri Lankans returning from overseas and the Navy proving to be an intractable source of infection among its soldiers.

\section{New opportunities for research, policy dialogue and training}

Social sciences will be required to play a major role in preventing a possible second attack of COVID-19 epidemic as well as in facilitating economic recovery, social rehabilitation and democratic governance in the aftermath of the pandemic. I list below some important areas where social science contribution to research and policy formulation will be urgently needed.

1. The reintegration of workers returning from overseas in a way that makes a useful contribution to innovation, capital formation and enterprise development in Sri Lanka.

2. Healing of cleavages reinforced during war, postwar and pandemic eras. This may call for a vigorous program of community development, social reconciliation and reintegration of marginalised communities at all levels.

3. An educational reform facilitating interaction among children across the ethnoreligious and class divide, development of practical and critical skills and school to work transition, including a program of practical experience in relevant government, nongovernment and private sector agencies.

4. A public sector reform contributing to improved governance, accountability and improved efficiency and enhanced productivity of workers at all levels with a sense of service to the public.
5. Improved social welfare programs with better targeting of beneficiaries, enhanced benefits to the deserving and proper evaluation of the programs in order to make sure that the welfare targets are met and at least some people periodically exit the thresholds of poverty and vulnerability using the services available.

6. Programs designed for rehabilitation of people connected with the underworld, drug trafficking and other organised crime. This has proved to be a major challenge for maintaining law and order in the country. Professional inputs from social science disciplines like sociology, social work and criminology will be needed for addressing this serious social problem.

It will be necessary for social science researchers in the country to contribute to these processes through research, dissemination and policy analysis. At the same time the study programs in various universities in the country should contribute towards meeting the human power requirements of these diverse programs.

\section{REFERENCES}

Latour, B. (1997) The trouble with the actor-network theory, Danish Philosophy Journal, 25(03), pp:47-64.

Metzler, K. (2020) What social science can offer us in a time of COVID-19, Times Higher Education, 18 April [Online] Available from: https:/www.timeshighereducation.com/blog/ what-social-science-can-offer-us-time-covid-19 [Accessed: $2^{\text {nd }}$ July 2020].

Roy, A. (2020) Indian racism towards Black people is almost worse than white peoples' racism- An email interview with Arundhati Roy for Dalit Camera, 8 June [Online] Available from: https://www.dalitcamera.com/indian-racism-towardsblack-people-is-almost-worse-than-white-peoples-racism/ [Accessed: $1^{\text {st }}$ July 2020].

Silva, K. T. (2020) Identity, infection and fear: a preliminary analysis of COVID-19 drivers and responses in Sri Lanka, Colombo: International Centre for Ethnic Studies (ICES) [Online] Available from: http://ices.lk/publications/identityinfection-and-fear/ [Accessed: $1^{\text {st }}$ July 2020].

Wood, E. J., Rogers, D., Sivaramakrishnan, K. and Almeling, R. (2020) Resuming field research in pandemic times. items: insights from social sciences, Social Science Research Council (SSRC)- Items- Insights from Social Sciences [Online] Available from: https://items.ssrc.org/covid-19-and-thesocial-sciences/social-research-and-insecurity/resuming-fieldresearch-in-pandemic-times/ [Accessed: $1^{\text {st }}$ July 2020].

Kalinga Tudor Silva 